\title{
Stand structural diversity and species with leaf nitrogen conservative strategy drive aboveground carbon storage in tropical old-growth forests
}

\section{Genzhu Wang}

Beijing Forestry University

\section{Yuguo Liu}

Chinese Academy of Forestry

\section{Xiuqin Wu}

Beijing Forestry University

\section{Danbo Pang}

Ningxia University

\section{Xiao Yang}

National Forestry and Grassland Adiministration

\section{Azfar Hussain}

Beijing Forestry University

Jinxing Zhou ( $\nabla$ zjx001@bjfu.edu.cn )

Beijing Forestry University

\section{Research}

Keywords: Biodiversity-ecosystem functioning, species diversity, functional diversity, functional compositions, stand structural diversity, elevation

Posted Date: May 13th, 2020

DOI: https://doi.org/10.21203/rs.3.rs-27540/v1

License: (a) (1) This work is licensed under a Creative Commons Attribution 4.0 International License. Read Full License 


\section{Abstract}

Background: Tropical old-growth forest ecosystems are essential for global carbon regulation. Even there are mounting evidences for the significance of species and functional composition, stand structure and elevation gradients on aboveground carbon storage, the relative strengths of these drivers and whether elevation effects via biotic factors are not clear. Furthermore, the mechanisms (the mass-ratio hypothesis or niche complementarity hypothesis) are still poorly understood.

Methods: We analyzed aboveground carbon storage, species diversity, stand structural diversity, community-weighted mean (CWM) of functional traits and functional diversity (FDvar) using date from 56 old-growth forest communities with different elevation gradients in Dawei mountain of southwestern China. Multiple regression models were used to test the relative importance of the predictor variables and structural equation model was used to explore the direct and indirect influences on the aboveground carbon storage.

Results: Our optimal multiple regression model show aboveground carbon storage is mostly affected by diameter at breast height (DBH) diversity, followed by FDvar of dry matter concentration in mature leaves and CWM nitrogen concentration in young leaves. The final structural equation model indicates elevation indirectly affected aboveground carbon storage via DBH diversity. The stand structural diversity, but not species diversity or functional diversity, enhanced aboveground carbon storage.

Conclusions: Our results indicate mass-ratio and niche complementarity effect promote aboveground carbon storage simultaneously. The complex stand structure and species with leaf nitrogen conservative strategy were the crucial drivers of aboveground carbon storage in tropical old-growth forests.

\section{Background}

Tropical forests are essential in global carbon (C) regulation (Saatchi et al. 2011). There are increasing evidence demonstrated the relationships between ecosystem functioning and biodiversity in natural forests (Lohbeck et al. 2016; Yuan et al. 2018a; Li et al. 2019). Although many studies supported the species diversity enhanced the aboveground C storage (Poorter et al. 2015; Li et al. 2019), other studies disagree (Cavard et al. 2010; Ruiz-Jaen et al. 2011; Fotis et al. 2018). The inconsistent results state that the relationships between ecosystem functioning and biodiversity needs to be further clarified (Fotis et al. 2018; Li et al. 2019), especially the multivariate mechanisms simultaneously affecting ecosystem functioning and biodiversity (Li et al. 2019).

The mass ratio hypothesis (Grime et al. 1998) and niche complementarity hypothesis (Tilman et al. 1997) are the two main mechanisms how species diversity would influence ecosystem functioning. The niche complementarity hypothesis demonstrates functional diversity (FDvar) and species diversity could increase the efficiency of resource utilization, thereby increasing $C$ storage (Díaz et al. 2011). The mass ratio hypothesis predicts the main species in the community determined ecosystem functions and can be examined by the correlations between ecosystem functioning and community-weighted mean (CWM) 
functional traits (Díaz et al. 2007). And, the species that enhanced ecosystem functioning may be differently dominated by conservative or acquisitive traits (Conti et al. 2013; Prado-Junior et al. 2016; Ali et al. 2017). There are studies supporting the niche complementarity hypothesis (Morin et al. 2011; Zhang et al. 2012; Cavanaugh et al. 2014) and mass ratio hypothesis (Lin et al. 2016; Fotis et al. 2018), which were found not exclusive to each other (Li et al. 2019).

Stand structural diversity was also demonstrated to represent facilitation and niche differentiation drive the ecosystem functions in recent years (Zhang and Chen. 2015; Poorter et al 2015; Yuan et al. 2018a). Multilayered stand structures promote more efficient use of light via better crown space allocation (Yachi and Loreau. 2007). Meanwhile functional diversity and species diversity could affect the ecosystem functioning through stand structural diversity indirectly (Chiang et al. 2016; Ali et al. 2016; Dănescu et al. 2016;). Thus, it is crucial to consider species diversity, stand structural diversity, functional dominance and functional diversity simultaneously to test the mechanisms and the drivers' relative importance (Li et al. 2019).

Abiotic factors were also the important drivers of aboveground $\mathrm{C}$ storage through determining plant survival and growth (Sullivan et al. 2017; Li et al. 2019). Microclimate impacts species abundances and distribution (Murphy et al. 2015), which in turn affects both biological and physical stand attributes (Fahey et al. 2015). Thus, abiotic factors could indirectly affect $\mathrm{C}$ storage by affecting biotic factors (Fotis et al. 2018; Li et al. 2019). Elevation, considered as a comprehensive factor reflecting climate, negatively affected the ecosystem functioning (Fotis et al. 2018). Meanwhile, Cavanaugh (2014) reported elevation was negatively correlated with species diversity and functional diversity, however, no effect was found on $\mathrm{C}$ storage.

In this study, we address three questions using 56 plots in tropical natural forests in southwestern China. First, how biotic (species diversity, stand structural diversity, functional diversity and functional composition) and abiotic (elevation gradients) factors drive aboveground C storage? Second, how these predictor variables relatively drive aboveground $\mathrm{C}$ storage. Third, how the predictor variables directly or indirectly influence aboveground C storage. Thus, we hypothesize (1) species diversity, stand structural diversity and functional diversity can enhance aboveground C storage simultaneously (2) CWM functional traits affected aboveground $\mathrm{C}$ storage positively or negatively; (3) elevation negatively affects aboveground $\mathrm{C}$ storage; elevation can also indirectly affect aboveground $\mathrm{C}$ storage via biotic factors.

\section{Material And Methods}

Site description and plots design

Our study was conducted in Dawei Mountain area $\left(22^{\circ} 35^{\prime}-23^{\circ} 07^{\prime} \mathrm{N}, 103^{\circ} 20^{\prime}-104^{\circ} 03^{\prime} \mathrm{E}\right)$, located in Yunnan Province, Southwestern China. The annual rainfall is $1700-1900 \mathrm{~mm}$. The annual average temperature is $22.6{ }^{\circ} \mathrm{C}$. The coldest month (January) is $15.2^{\circ} \mathrm{C}$ and the hottest month (July) is $27.7^{\circ} \mathrm{C}$. There is no frost in the whole year. The elevation range between $225 \mathrm{~m}$ and $2365 \mathrm{~m}$ for the highest peak of Dajian Mountain. The forest types change significantly from the bottom to the top of mountain. 
In order to ensure the comparability of forest communities in different elevation gradients, only oldgrowth forests far away from disturbance were selected. A vegetation and soil comprehensive investigation was conducted before plot selection. With the help of local forestry department, four elevation gradients, containing $800 \mathrm{~m}, 1200 \mathrm{~m}, 1600 \mathrm{~m}$ and $2000 \mathrm{~m}$, respectively were selected and fourteen $20 \mathrm{~m} \times 20 \mathrm{~m}$ plots were set with a distance more than $100 \mathrm{~m}$ for each plot in each elevation gradient. Total 56 plots were selected. Between 2017-2018, all the individual trees were identified in the plot or lab through the collected specimen to species level (Li et al. 2019). Details of species composition are listed in Annex 1 of Additional file 1.

\section{Quantification of aboveground C storage}

We measured the diameter at breast height (DBH) of all the trees with $\mathrm{DBH}$ higher than $5 \mathrm{~cm}$ in each plot. The telescopic pole was used to measure tree height lower than $18 \mathrm{~m}$ and the clinometer was used for the height measurement for the other trees. The allometric equation, which was according to height, DBH and wood density, was used to calculate the aboveground biomass of individuals whose DBH were higher than $5 \mathrm{~cm}$ (Chave et al. 2014). Aboveground $\mathrm{C}$ storage was calculated by multiplying aboveground biomass by 0.5 (Chave et al. 2005). Wood density for most species were obtained from field investigation and other species' wood density were used the wood density of average family or average wood density of corresponding plot (Cavanaugh et al. 2014). The global allometric equation was calculated as follows:

\section{$A G B=0.0673 \times\left(\rho \times \mathrm{DBH}^{2} \times \mathrm{H}\right)^{0.976}$}

where $\rho$ represents the wood density $\left(\mathrm{g} \mathrm{cm}^{-3}\right), \mathrm{H}$ represents the height $(\mathrm{m}), \mathrm{DBH}$ represents diameter at breast height $(\mathrm{cm})$.

The quantification of stand structural and species diversity

Species and stand structural (height and $\mathrm{DBH}$ ) diversity were quantified by Shannon-Wiener biodiversity index (Ali et al. 2016). Recommended by Ali et al (2016), different DBH classes $(8,6,4$, and $2 \mathrm{~cm}$ ) and height classes $(5,4,3$, and $2 \mathrm{~m}$ ) were calculated. The proportions of individual species, height class and DBH class was represented by the relative basal area (Finegan et al. 2015; Ali et al. 2016). Because the different discrete height and DBH diversity classes may predict aboveground $\mathrm{C}$ storage differently, relationships between aboveground $\mathrm{C}$ storage and each class of stand structural diversity were elevated and the lowest AIC values were used to select the classes used for the models in Annex 2 of Additional file 1 (Yuan et al. 2018b).

\section{Functional traits}

Leaf nitrogen concentration (LNC), leaf phosphorus concentration (LPC), N:P ratio, specific leaf area (SLA), leaf dry matter content (LDMC) and leaf thickness (LT), which were crucial for plant survival and growth (Wright et al. 2010; Finegan et al. 2015; Ali et al. 2017), were measured of all the species in the 
plots in both young and mature leaves, on account of the central plant trade-offs strongly correlating with leaf longevity (Aerts et al. 2000; Ali et al. 2017). All the leaf functional traits were measured based on standard measurement methods (Pérez-Harguindeguy et al. 2013).

The calculation of CWM trait values in each plot were based on the following formula (Conti and Díaz., 2013; Ali et al., 2017):

\section{$\operatorname{CWM}\left(\right.$ trait $\left._{\mathrm{X}}\right)=\sum_{\mathrm{i}=1}^{\mathrm{s}} \mathrm{p}_{\mathrm{i}} \times \mathrm{x}_{\mathrm{i}}$}

where CWM (trait ${ }_{\mathrm{X}}$ ) represents the CWM X trait, s represents the species number in each plot, $\mathrm{p}_{\mathrm{i}}$ represents $i$ th species' relative abundance in the plot and $x_{i}$ represents the $i$ th species' trait value.

Functional diversity was calculated as follows (Conti and Díaz. 2013):

$$
\text { FDvar }=2 / n a r c t a n(5 V) \text { and } V=\sum_{i=1}^{S} p_{i}\left(\ln x_{i}-\ln x\right)^{2}
$$

where $p_{i}=a_{i} / \sum_{i=1}^{S} a_{i}$, ai represents $i$ th species' relative abundance in the plot, $x_{i}$ represents the $i$ th

species' trait value, $\ln \mathrm{x}=\sum_{\mathrm{i}=1}^{\mathrm{s}} \mathrm{p}_{\mathrm{i}} \ln \mathrm{x}_{\mathrm{i}}$. The variation range of FDvar values is 0 to 1 .

Statistical analyses

One-way ANOVA and least square difference (LSD) multiple comparison tests were used to test the difference in aboveground $\mathrm{C}$ storage and abiotic factors among different elevations (Annex 3 of Additional file 1). Pearson correlation coefficients were employed to investigate the relationships among aboveground $\mathrm{C}$ storage, species diversity, functional dominances, functional diversity, stand structural diversity and elevation in Annex 1 of Additional file 2 (Li et al. 2019). Shapiro-Wilk test was used to examine the normality of all the date (Zhang et al. 2012). Non-normal continuous variables were naturallogarithm-transformed to improve normality and linearity before the date statistics (Zhang et al. 2012; Li et al. 2019).

Simple and multiple linear regressions were employed to explore the relationships between aboveground $\mathrm{C}$ storage and explanatory variables ( $\mathrm{Li}$ et al. 2019). The combination of 28 indices yields total 268435455 models, which were beyond the capacity of R (Ali et al. 2017). To select the optimal subset of predictor variables of the aboveground $\mathrm{C}$ storage, ordinary least squares multiple regression analyses was first conducted with all 12 CWM indices, resulting 4095 possible models. Then we used the other 15 biotic indices (FDvar, species diversity and stand structural diversity) to conduct multiple regression analyses, which resulted 32367 possible models. Finally, we combined the elevation with the two former best subsets of predictors to conduct multiple analyses and the 8 predict variables resulted 255 possible models. All possible models were evaluated with corrected Akaike information criterion (AICC) and the 
best-fit regression model were selected based on the lowest AICc values (Li et al. 2019; Wen et al. 2019). Multicollinearity was diagnosed by variance inflation factor (VIF) and all VIF values were lower than 10 in the best-fit regression model, which suggested our results were not affected by collinearity among predictor variables (Graham 2003). Detailed statistics of all models are provided in Annex 2 of Additional file 2, respectively. The 'glmulti' package in R 3.6.1 was used to select models (Calcagno 2013).

Structural equation model (SEM), which was widely used to explore the complex relationships between ecosystem functioning and predictor variables (van der Sande et al. 2017), were conducted to invest how the biotic and abiotic factors affect aboveground $C$ storage directly or indirectly. The variables retained in the best-fit regression model were used to construct SEM (Ali et al. 2017; Wen et al. 2019). The comparative fit index (CFI), goodness-of-fit index (GFI), root mean square error of approximation (RMSEA), Chi-square $\left(\chi^{2}\right)$ test and AIC were employed to test the fitness of SEM (Zhang and Chen. 2015). The SEM were implemented using the AMOS 21.0 software.

\section{Results}

Correlations between aboveground $\mathrm{C}$ storage and influencing factors

Aboveground $C$ storage was most strongly affected by DBH $\left(R^{2}=0.413, P<0.001\right)$ and height $\left(R^{2}=0.207\right.$, $P<0.001$ ) diversity (Figure. 1). The CWM nitrogen concentration of young leaves negatively affected aboveground $C$ storage $\left(R^{2}=0.08, P=0.034\right)$. Aboveground $C$ storage decreased with FDvar of LDMC and SLA in both young and mature leaves. The FDvar of phosphorus concentration in young leaves $\left(R^{2}=\right.$ $0.072, P=0.045)$ and elevation gradients $\left(\mathrm{R}^{2}=0.067, P=0.03\right)$ also negatively affected aboveground $\mathrm{C}$ storage.

The relative importance of all predictor variables for aboveground $\mathrm{C}$ storage

Only 4 predictor variables were retained in the optimal multiple regression model, account for $57.21 \%$ of the variation in aboveground $\mathrm{C}$ storage (Table 1 ). DBH diversity still most importantly affected aboveground $C$ storage $(P<0.001, \beta=0.47)$. The FDvar of leaf dry matter content in mature leaves $(P=$ $0.009, \beta=-0.27)$ and CWM nitrogen concentrations of young leaves $(P=0.011, \beta=-0.25)$ both negatively affected aboveground $\mathrm{C}$ storage significantly. The height diversity didn't significantly affect the aboveground $\mathrm{C}$ storage in the final multiple regression model $(P=0.081, \beta=-0.18)$. 
Table 1

The optimal model resulted from a sequence of regression analyses of aboveground carbon storage.

\begin{tabular}{|c|c|c|c|c|c|c|}
\hline Model and predictor & Coeff. & Beta & $t$ & $P$ & $R^{2}$ & AlCc \\
\hline \multicolumn{7}{|c|}{ Effects of community-weighted mean (CWM) } \\
\hline Model ${ }^{1}$ & & & & $<0.001$ & 0.28 & 105.52 \\
\hline Constant & 9.20 & 0 & 7.21 & $<0.001$ & & \\
\hline CWM SLA-Y & -0.01 & -0.39 & -2.33 & 0.024 & & \\
\hline CWM LT-Y & -2.66 & -0.46 & -3.21 & 0.002 & & \\
\hline CWM LNC-Y & -0.02 & -0.34 & -2.70 & 0.009 & & \\
\hline CWM LDMC-M & -5.35 & -0.44 & -0.28 & 0.007 & & \\
\hline \multicolumn{7}{|c|}{ Effects of functional diversity (FDvar), species diversity and stand structural diversity } \\
\hline Mode ${ }^{R}$ & & & & $<0.001$ & 0.51 & 80.80 \\
\hline Constant & 3.35 & 0 & 14.36 & $<0.001$ & & \\
\hline FDvar LDMC-M & -1.17 & -0.27 & -2.59 & 0.012 & & \\
\hline DBH Diversity & 1.85 & 0.49 & 4.24 & $<0.001$ & & \\
\hline Height Diversity & 0.53 & 0.17 & 1.60 & 0.116 & & \\
\hline \multicolumn{7}{|c|}{ Joint effect of all predict variables } \\
\hline Mode $\beta$ & & & & $<0.001$ & 0.57 & 76.18 \\
\hline Constant & 4.14 & 0 & 11.15 & $<0.001$ & & \\
\hline CWM LNC-Y & -0.02 & -0.25 & -2.65 & 0.011 & & \\
\hline FDvar LDMC-M & -1.16 & -0.27 & -2.73 & 0.009 & & \\
\hline DBH Diversity & 1.78 & 0.47 & 4.30 & $<0.001$ & & \\
\hline Height Diversity & 0.56 & 0.18 & 1.78 & 0.081 & & \\
\hline
\end{tabular}

Note: The regression coefficient (Coeff.), standardized regression coefficient (Beta), t-test and $P$-value are given for each predictor variable. For the model, the coefficient of determination $\left(\mathrm{R}^{2}\right), P$-value and Akaike Information Criterion (AICC) are also given. $P$ values $<0.05$ are given in bold.

The direct and indirect impacts on aboveground C storage

The optimal SEM accounted for 53,13,5, 2 and $1 \%$ of the variation in aboveground $C$ storage, DBH diversity, height diversity, FDvar of LDMC in mature leaves and CWM nitrogen concentration in young 
leaves (Figure. 2). The DBH diversity directly enhanced aboveground $C$ storage significantly $(P=0.002, \beta$ $=0.48)$, whereas CWM young leaves' nitrogen concentration $(P=0.009, \beta=-0.27)$ and FDvar of mature leaves' dry matter content $(P=0.034, \beta=-0.27)$ both had significant negative direct effect (Figure. 2, Table 2). Elevation negatively affected DBH diversity directly $(P<0.001, \beta=-0.37)$ and didn't affect aboveground $\mathrm{C}$ storage directly $(P=0.906, \beta=-0.02)$. However, elevation had a significant negative indirect effect via DBH diversity $(P=0.002, \beta=-0.18)$. The total effect of elevation was significant $(P=$ $0.044, \beta=-0.30)$.

Table 2

The direct, indirect, and total standardized effects on aboveground carbon storage based on structural equation model.

\begin{tabular}{|llll|}
\hline Predictor & Pathway to aboveground carbon storage & Effect & $P$-value \\
\hline Elevation & Direct effect & -0.02 & 0.906 \\
\cline { 2 - 4 } & Indirect effect via DBH diversity & -0.18 & 0.002 \\
\cline { 2 - 4 } & Indirect effect via height diversity & -0.04 & 0.057 \\
\cline { 2 - 4 } & Indirect effect via CWM LNC-Y & -0.02 & 0.412 \\
\cline { 2 - 4 } & Indirect effect via FDvar LDMC-M & -0.04 & 0.245 \\
\cline { 2 - 4 } & Total effect & -0.30 & 0.044 \\
\hline DBH Diversity & Direct effect & 0.48 & $<0.001$ \\
\hline CWM LNC-Y & Direct effect & 0.19 & 0.057 \\
\hline FDvar LDMC-M & Direct effect & -0.27 & 0.003 \\
\hline
\end{tabular}

Note: The indirect effect of elevation was calculated by multiplying the standardized effects of all paths on one route, from elevation to mediator, and then to aboveground carbon storage, while the total effect was calculated by adding standardized direct and indirect effects.

\section{Discussion}

Biodiversity promoting ecosystem functioning has long been debated during last two decades (Forrester and Bauhus. 2016). Inconsistent with the hypothesis, no correlation between aboveground C storage and species diversity was found, which may be caused by a potent effect of the dominant productive species (Cardinale et al. 2011; Tobner et al. 2016; Fotis et al. 2018) or competition exclusion (Grime. 1973; Grace et al. 2016; Ali et al. 2016). In natural forests, species richness may achieve saturation and previous studies have reported ecological niches of the most species were overlapping, which may reduce the influence of species diversity on ecosystem functioning (Silver et al. 1996; Hooper et al. 2005; Ruiz-Jaen et al. 2011). As expected, both the DBH and height diversity promoted ecosystem functioning, consistent 
with recent researches (Dănescu et al. 2016; Ali et al. 2016; Forrester and Bauhus. 2016; Fotis et al. 2018). These may result from multilayered forest structure enhancing the capture of water, light, and soil nutrients (Forrester. 2014; Poorter et al. 2015). No correlation was found between stand structure diversity and species diversity (Annex 1 of Additional file 2), inconsistent with the hypothesis and previous results (Zhang and Chen. 2015; Ali et al. 2016). The variations among and within species could result in the differences of stand structure (Clark 2010; Zhang et al. 2012) and this result potentially stressed the importance of variations within species.

Unexpected, significant negative associations between FDvar of leaf functional traits and aboveground C storage were found, which was not consistent with the niche complementarity hypothesis and some previous results (Ali et al. 2016). Functional diversity is positively related to species diversity (Annex 1 of Additional file 2) and low trait diversity maybe caused by the large dominated species (Van Gelder et al. 2006). The results provide a potential solution to stand structure (Zhang and Chen 2015; Dănescu et al. 2016; Forrester and Bauhus 2016; Ali et al. 2016; Fotis et al. 2018) as the niche complementarity mechanism to maintenance ecosystem functioning, but not the species diversity (Cavard et al. 2010; Ruiz-Jaen et al. 2011; Ali et al. 2016) or the functional diversity (Conti et al. 2013; Cavanaugh et al. 2014; Finegan et al. 2015; Fotis et al. 2018).

The CMM nitrogen concentration of young leaves negatively related to aboveground $\mathrm{C}$ storage, consistent with our hypothesis and previous studies (Finegan et al. 2015; Ali et al. 2017). Our result indicates mass ratio hypothesis is essential for promoting ecosystem functioning (Finegan et al. 2015) and plant's leaf economic spectrum correlated with the aboveground C storage (Garnier et al. 2004). The high aboveground C storage was accompanied by low CWM leaf nitrogen concentration, which indicate "slow" forests result in high aboveground C storage accumulation in old-growth forests (Quesada et al. 2012). Conservative resource use syndromes were associated with low $\mathrm{C}$ losses through mortality (Wright et al. 2010) or decomposition (Wright et al. 2004; Conti and Díaz 2013;). In old-growth communities, the adaptions that forests were dominated by conservative species might result in less biomass turnover and more aboveground C storage (Ruiz-Jaen et al. 2011; Conti and Díaz 2013).

As expected, the aboveground $C$ storage decreased significantly with the elevation gradient increasing, which was consistent with previous results (Fotis et al. 2018). The DBH diversity, CWM SLA and LPC decreased and CWM LT increased with the elevation increasing (Annex 4 of Additional file 1), which indicated the elevation had significant filtering effect (Grime. 2006). These leaf conservative resource use syndromes and low stand structural diversity at higher elevations may result from adaptions of plants to the harsh environment (Read et al. 2014). As hypothesized, the elevation gradient can also indirectly affect the aboveground $\mathrm{C}$ storage via the stand structural diversity, which was consistent with previous studies where climate factors indirectly affected aboveground $\mathrm{C}$ storage via forest compositions (van der Sande et al. 2017; Li et al. 2019). Unexpected, we didn't find elevation indirectly affect aboveground C storage via or species diversity or leaf functional traits. 
We found the stand structure diversity was the most important driver of aboveground $\mathrm{C}$ storage, followed by CWM LNC and FDvar of leaf traits. This result indicates niche complementarity may have a more important effect on promoting ecosystem functioning than mass-ratio effect. Both consideration the niche complementarity and mass-ratio effect simultaneously can better explain the mechanisms of ecosystem function (Table 1). However, it must be noted that some other functional traits, such as plant diameters (Cavanaugh et al. 2014; Finegan et al. 2015), wood traits (Ali et al. 2017) and leaf anatomical traits (He et al. 2016) affecting ecosystem functioning were not measured in this study. And dynamic of other ecosystem functioning (e.g. aboveground productivity) maybe not consistent with aboveground $\mathrm{C}$ storage (Chisholm et al. 2013). Meanwhile, ecosystem functioning and biotic factors changed with succession (Lohebeck et al. 2013; Ali et al. 2016; Ali et al. 2017) and other abiotic factors, such as soil nutrients (Zhang and Chen. 2015; Yuan et al. 2018a) and climate factors (Li et al. 2019). Thus, we encourage more studies investigating the relationships between ecosystem functioning and biodiversity taking into consideration the predictor variables simultaneously in communities of different stages of succession.

\section{Conclusions}

The date from 56 old-growth forest plots indicate both niche complementarity and mass-ratio effect are essential in promoting ecosystem functioning. The stand structural diversity strongly enhanced the aboveground $\mathrm{C}$ storage, but not the species diversity or functional diversity. The species dominated by leaf nitrogen conservative strategy drive the aboveground $\mathrm{C}$ storage. Elevation has a significant filtering effect on DBH diversity and CWM leaf functional traits. The elevation indirectly affected the aboveground $\mathrm{C}$ storage via DBH diversity. Our results indicated complex stand structure and species with leaf nitrogen conservative use strategy can maximize aboveground $\mathrm{C}$ storage in tropical old-growth forests.

\section{Abbreviations}

AGC: aboveground carbon storage; CWM: community-weighted mean; FDvar: functional diversity; LDMC: leaf dry matter content; SLA: specific leaf area; LT: leaf thickness; LNC: leaf nitrogen concentration; LPC: leaf phosphorus concentration; N:P: N:P ratio; Y: young leaves; M: mature leaves $\triangle D B H$ : diameter at breast height.

\section{Declarations}

\section{Acknowledgements}

We gratefully acknowledge all those who have participated in the field investigation and laboratory test. We are also grateful to Pinrong Li, Yongxing Chu and Yong Chai for the species identify in the field and laboratory.

\section{Authors' contributions}


JZ, GW and YL collected and analyzed the data and were major contributors in writing the manuscript. $\mathrm{XW}, \mathrm{DP}, \mathrm{XY}$ and $\mathrm{AH}$ made substantial contributions to the conception and design, the interpretation of data and writing of the manuscript. All authors read and approved the final manuscript.

\section{Funding}

This study was supported by the National Natural Science Foundation of China $(31870707,41671080)$ and the National Key R\&D Program of China (2016YFC0502504). We are grateful to the Beijing Municipal Education Commission for their financial support through Innovative Transdisciplinary Program "Ecological Restoration Engineering".

\section{Availability of data and materials}

The datasets analyzed during the current study are available from the corresponding author upon request.

\section{Ethics approval and consent to participate}

Not applicable.

\section{Consent for publication}

Not applicable.

\section{Competing interests}

The authors declare that they have no competing interests.

\section{Author details}

1 Jianshui Research Station, School of Soil and Water Conservation, Beijing Forestry University, Beijing 100083, China. ${ }^{2}$ Key Laboratory of State Forestry Administration on Soil and Water Conservation, Beijing Forestry University, Beijing 100083, China. ${ }^{3}$ Institute of Desertification Studies, Chinese Academy of Forestry, Beijing 100091, China. ${ }^{4}$ Breeding Base for State Key Laboratory of Land Degradation and Ecological Restoration in Northwest China, Ningxia University, Yinchuan 750021, China. ${ }^{5}$ Academy of Forest Inventory and Planning, National Forestry and Grassland Administration『Beijing 100714, China.

\section{References}

1. Aerts R, Chapin F, Fitter A, Raffaelli D (2000) The mineral nutrition of wild plants revisited: a reevaluation of processes and patterns. Adv Ecol Res 30:1-67

2. Ali A, Yan ER, Chen HYH, Chang SX, Zhao YT, Yang XD, Xu MS (2016) Stand structural diversity rather than species diversity enhances aboveground carbon storage in secondary subtropical forests in eastern China. Biogeosciences 13(6):4627-4635 
3. Ali A, Yan ER, Chang SX, Cheng JY, Liu XY (2017) Community-weighted mean of leaf traits and divergence of wood traits predict aboveground biomass in secondary subtropical forests. Sci Total Environ 574:654-662

4. Calcagno V (2013) glmulti: model selection and multimodel inference made easy. R Package Version 1.0.7.1 (pp. Model selection and model averaging based on information criteria (AIC, AICc or BIC))

5. Cardinale BJ, Matulich KL, Hooper DU, Byrnes JE, Duffy E, Gamfeldt L, Balvanera P, O'Connor MI, Gonzalez A (2011) The functional role of producer diversity in ecosystems. Am J Bot 98(3):572-592

6. Cavard X, Bergeron Y, Chen HYH, Pare D (2010) Mixed-species effect on tree aboveground carbon pools in the east-central boreal forests. Can J For Res 40(1):37-47

7. Cavanaugh KC, Gosnell JS, Davis SL, Ahumada J, Boundja P, Clark DB, Mugerwa B, Jansen PA, O'Brien TG, Rovero F, Sheil D, Vasquez R, Andelman S (2014) Carbon storage in tropical forests correlates with taxonomic diversity and functional dominance on a global scale. Glob Ecol Biogeogr 23(5):563-573

8. Chave J, Andalo C, Brown S, Cairns MA, Chambers JQ, Eamus D, Folster H, Fromard F, Higuchi N, Kira T, Lescure JP, Nelson BW, Ogawa H, Puig H, Riéra B, Yamakura T (2005) Tree allometry and improved estimation of carbon stocks and balance in tropical forests. Oecologia145(1): 87-99

9. Chave J, Rejou-Mechain M, Burquez A, Chidumayo E, Colgan M, Delitti W, Duque A (2014) Improved allometric models to estimate the aboveground biomass of tropical trees. Glob Chang Biol 20(10):3177-3190

10. Chiang JM, Spasojevic MJ, Muller-Landau HC, Sun IF, Lin Y, Sus SH, Chen Z, Chen CT, Swenson NG, McEwan RW (2016) Functional composition drives ecosystem function through multiple mechanisms in a broadleaved subtropical forest. Oecologia 182(3):829-840

11. Chisholm RA, Muller-Landau HC, Abdul Rahman K, Bebber DP, Bin Y, Bohlman SA (2013) Scaledependent relationships between tree species richness and ecosystem function in forests. $J$ Ecol 101:1214-1224

12. Clark JS (2010) Individuals and the variation needed for high species diversity in forest trees. Science 327(5969):1129-1132

13. Conti G, Díaz S (2013) Plant functional diversity and carbon storage - an empirical test in semi-arid forest ecosystems. J Ecol 101(1):18-28

14. Dănescu A, Albrecht AT, Bauhus J (2016) Structural diversity promotes productivity of mixed, unevenaged forests in southwestern Germany. Oecologia 182(2):1-15

15. Diaz S, Lavorel S, de Bello F, Quetier F, Grigulis K, Robson M (2007) Incorporating plant functional diversity effects in ecosystem service assessments. Proc Natl Acad Sci 104(52):20684-20689

16. Díaz S, Quétier F, Cáceres DM, Trainor SF, Pérez-Harguindeguy N, Bret-Harte MS, Finegan B, PeñaClaros M, Poorter $L$ (2011) Linking functional diversity and social actor strategies in a framework for interdisciplinary analysis of nature's benefits to society. Proc Natl Acad Sci 108(3):895-902

17. Fahey RT, Fotis AT, Woods KD (2015) Quantifying canopy complexity and effects on productivity and resilience in late successional hemlock-hardwood forests. Ecol Appl 25:834-847 
18. Finegan B, Peña-Claros M, Oliveira A, Ascarrunz N, Bret-Harte MS, Carreño-Rocabado G, Casanoves F, Díaz S, Eguiguren Velepucha P, Fernandez F, Juan Carlos L, Leda L, Beatriz Salgado N, Marcel V, Lourens $\mathrm{P}$ (2015) Does functional trait diversity predict above-ground biomass and productivity of tropical forests? Testing three alternative hypotheses. J Ecol 103:191-201

19. Forrester DI (2014) The spatial and temporal dynamics of species interactions in mixed-species forests: from pattern to process. For Ecol Manage 312:282-292

20. Forrester DI, Bauhus J (2016) A review of processes behind diversity-Productivity relationships in forests. Cur For Rep 2(1):45-61

21. Fotis AT, Murphy SJ, Ricart RD, Krishnadas M, Whitacre J, Wenzel JW, Queenborough SA, Comita LS (2018) Above-ground biomass is driven by mass-ratio effects and stand structural attributes in a temperate deciduous forest. J Ecol 106:561-571

22. Garnier E, Cortez J, Billes G, Navas ML, Roumet C, Debussche M, Laurent G, Blanchard A, Aubry D, Bellmann A, Neill C, Toussaint JP (2004) Plant functional markers capture ecosystem properties during secondary succession. Ecology 85(9):2630-2637

23. Grace JB, Anderson TM, Seabloom EW, Borer ET, Adler PB, Harpole WS, Hautier Y (2016) Integrative modelling reveals mechanisms linking productivity and plant species richness. Nature 529:390-393

24. Graham M (2003) Confronting multicollinearity in ecological multiple regression. Ecology 84(11):2809-2815

25. Grime JP (1973) Competitive exclusion in herbaceous vegetation. Nature 242(5396):344-347

26. Grime JP (1998) Benefits of plant diversity to ecosystems: immediate, filter and founder effects. J Ecol 86(6):902-910

27. Grime JP (2006) Trait convergence and trait divergence in herbaceous plant communities: mechanisms and consequences. J Veg Sci 17(2):255-260

28. He NP, Liu CC, Tian M, Li ML, Yang H, Yu GR, Guo DL, Smith MD, Yu Q, Hou JH (2017) Variation in leaf anatomical traits from tropical to cold-temperate forests and linkage to ecosystem functions. Funct Ecol 00:1-10

29. Hooper DU, Chapin FS, Ewel JJ, Hector A, Inchausti P, Lavorel S, Lawton JH, Lodge DM, Loreau M, Naeem S, Schmid B, Setala H, Symstad AJ, Vandermeer J, Wardle DA (2005) Effects of biodiversity on ecosystem functioning: a consensus of current knowledge. Ecol Monogr 75(1):3-35

30. Li Y, Bao W, Bongers F, Chen B, Chen GK, Guo K, Jiang MX, Lai JS, Lin DM, Liu CJ, Liu XJ, Liu Y, Mi XC, Tian XJ, Wang XH, Xu WB, Yan JH, Yang B, Zheng YR, Ma KP (2019) Drivers of tree carbon storage in subtropical forests. Sci Total Environ 654:684-693

31. Lin D, Anderson-Teixeira KJ, Lai J, Mi X, Ren H, Ma K (2016) Traits of dominant tree species predict local scale variation in forest aboveground and topsoil carbon stocks. Plant Soil 409(1-2):435-446

32. Lohbeck M, Bongers F, Martinez-Ramos M, Poorter L (2016) The importance of biodiversity and dominance for multiple ecosystem functions in a human-modified tropical landscape. Ecology 97:2772-2779 
33. Morin X, Fahse L, Scherer-Lorenzen M, Bugmann H (2011) Tree species richness promotes productivity in temperate forests through strong complementarity between species. Ecol Lett 14(12):1211-1219

34. Murphy SJ, Audino LD, Whitacre J, Eck JL, Wenzel JW, Queenborough SA, Comita LS (2015) Species associations structured by environment and land-use history promote beta-diversity in a temperate forest. Ecology 96(3):705-715

35. Petchey OL, Gaston KJ (2006) Functional diversity: back to basics and looking forward. Ecol Lett 9(6):741-758

36. Pérez-Harguindeguy N, Díaz S, Garnier E, Lavorel S, Poorter H, Jaureguiberry P (2013) New handbook for standardised measurement of plant functional traits worldwide. Aust J Bot 61(3):167-234

37. Poorter L, van der Sande MT, Thompson J, Arets EJMM, Alarcón A, Álvarez-Sánchez J (2015) Diversity enhances carbon storage in tropical forests. Glob Ecol Biogeogr 24(11):1314-1328

38. Prado-Junior JA, Schiavini I, Vale VS, Arantes CS, van der Sande MT, Lohbeck M, Poorter L (2016) Conservative species drive biomass productivity in tropical dry forests. J Ecol 104(3):817-827

39. Quesada CA, Phillips OL, Schwarz M, Czimczik Cl, Baker TR, Patio S, Fylla NM, Hodnett (2012) Basinwide variations in Amazon forest structure and function are mediated by both soils and climate. Biogeosciences 9(6):2203-2246

40. Read QD, Moorhead LC, Swenson NG, Bailey JK, Sanders NJ (2014) Convergent effects of elevation on functional leaf traits within and among species. Funct Ecol 28 (1)

41. Ruiz-Jaen MC, Potvin C (2011) Can we predict carbon stocks in tropical ecosystems from tree diversity? Comparing species and functional diversity in a plantation and a natural forest. New Phytol 189(4):978-987

42. Ruiz-Benito P, Gómez-Aparicio L, Paquette A, Messier C, Kattge J, Zavala MA (2014) Diversity increases carbon storage and tree productivity in Spanish forests. Glob Ecol Biogeogr 23(3):311-322

43. Saatchi SS, Harris NL, Brown S (2011) Benchmark map of forest carbon stocks in tropical regions across three continents. Proc Natl Acad Sci 108(24):9899-9904

44. Silver WL, Brown S, Lugo AE (1996) Effects of changes in biodiversity on ecosystem function in tropical forests. Conserv Biol 10(1):17-24

45. Sullivan MJ, Talbot J, Lewis SL, Phillips OL, Qie L, Begne SK, Chave J, Cuni-Sanchez A (2017) Diversity and carbon storage across the tropical forest biome. Sci Rep 7

46. Tilman D, Knops J, Wedin D, Reich P, Ritchie M, Siemann E (1997) The influence of functional diversity and composition on ecosystem processes. Science 277(5330):1300-1302

47. Tobner CM, Paquette A, Gravel D, Reich PB, Williams LJ, Messier C (2016) Functional identity is the main driver of diversity effects in young tree communities. Ecol Lett 19(6):638-647

48. Van Gelder HA, Poorter L, Sterck FJ (2006) Wood mechanics, allometry, and life-history variation in a tropical rain forest tree community. New Phytol 171:367-378 
49. van der Sande MT, Peña-Claros M, Ascarrunz N, Arets EJMM, Licona JC, Toledo M, Poorter L (2017) Abiotic and biotic drivers of biomass change in a Neotropical forest. J Ecol 105:1223-1234

50. Wen Z, Zheng H, Smith R, Zhao J, Liu H, Ouyang L ZY (2019) Functional diversity overrides community-weighted mean traits in linking land-use intensity to hydrological ecosystem services. Sci Total Environ 682:583-590

51. Wright IJ, Reich PB, Westoby M, Ackerly DD, Baruch Z, Bongers F, Cavender-Bares J (2004) The worldwide leaf economics spectrum. Nature 428(6985):821-827

52. Wright SJ, Kitajima K, Kraft NJB, Reich PB, Wright IJ, Bunker DE, Condit R, Dalling JW, Davies SJ, Díaz S, Engelbrecht BMJ, Harms KE, Hubbell SP, Marks CO, Ruiz-Jean MC, Salvador CM, Zanne AE (2010) Functional traits and the growth-mortality trade-off in tropical trees. Ecology 91(12):36643674

53. Yachi S, Loreau M (2007) Does complementary resource use enhance ecosystem functioning? A model of light competition in plant communities. Ecol Lett 10(1):54-62

54. Yuan ZQ, Ali A, Wang SP, Gazol A, Freckleton R, Wang XG, Lin F, Zhou L, Hao ZQ, Loreau M (2018a) Abiotic and biotic determinants of coarse woody productivity in temperate mixed forests. Sci Total Environ 630:422-431

55. Yuan ZQ, Wang SP, Ali A, Gazol A, Ruiz-Benito P, Wang XG, Lin F, Ye J, Hao ZQ, Loreau M (2018b) Aboveground carbon storage is driven by functional trait composition and stand structural attributes rather than biodiversity in temperate mixed forests recovering from disturbances. Ann Forest Sci 75(3):67-

56. Zhang Y, Chen HYH, Reich PB (2012) Forest productivity increases with evenness, species richness and trait variation: a global meta-analysis. J Ecol 100(3):742-749

57. Zhang Y, Chen HYH (2015) Individual size inequality links forest diversity and aboveground biomass. J Ecol 103:1245-1252

\section{Supplementary Information}

\section{Additional File 1}

Annex 1 Species composition in old-growth forests

Annex 2 General linear relationship between aboveground C storage and stand structural (tree diameter at breast height (DBH) and height) diversity of different classes across the plots. The bold discrete classes were selected.

Annex 3 Community characteristics across tropical mature forests in China. Mean and range (in parentheses). Lowercase letters represent significant pairwise differences between different elevation gradients $(P<0.05)$. 
Annex 4 Bivariate relationships between elevation (dependent) and exogenous (independent) variables ( $\mathrm{n}$ $=56)$. Only significant relationships are shown here $(P<0.05)$.

\section{Additional File 2}

Annex 1 Pearson correlation coefficients for pairwise comparisons between aboveground carbon storage and species diversity, stand structural diversity, functional diversity, functional compositions and elevation gradients, as well as for pairwise correlations between all independent variables.

Annex 2 Results for the Model Selection procedure, based on Akaike Information Criterion (AICc).

Figures
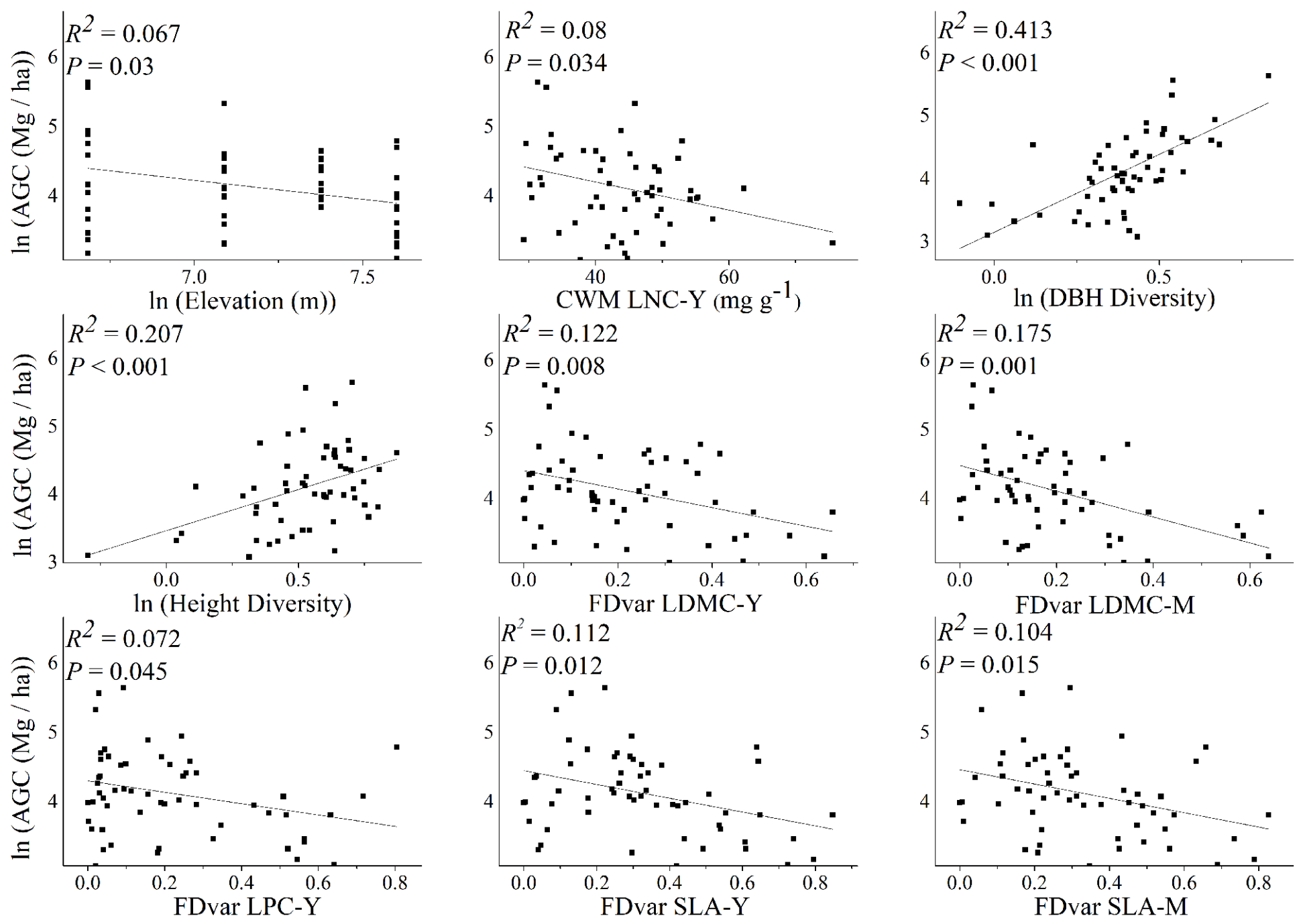

\section{Figure 1}

Significant bivariate relationships between aboveground carbon storage (AGC) and predictor variables ( $\mathrm{n}$ = 56). 


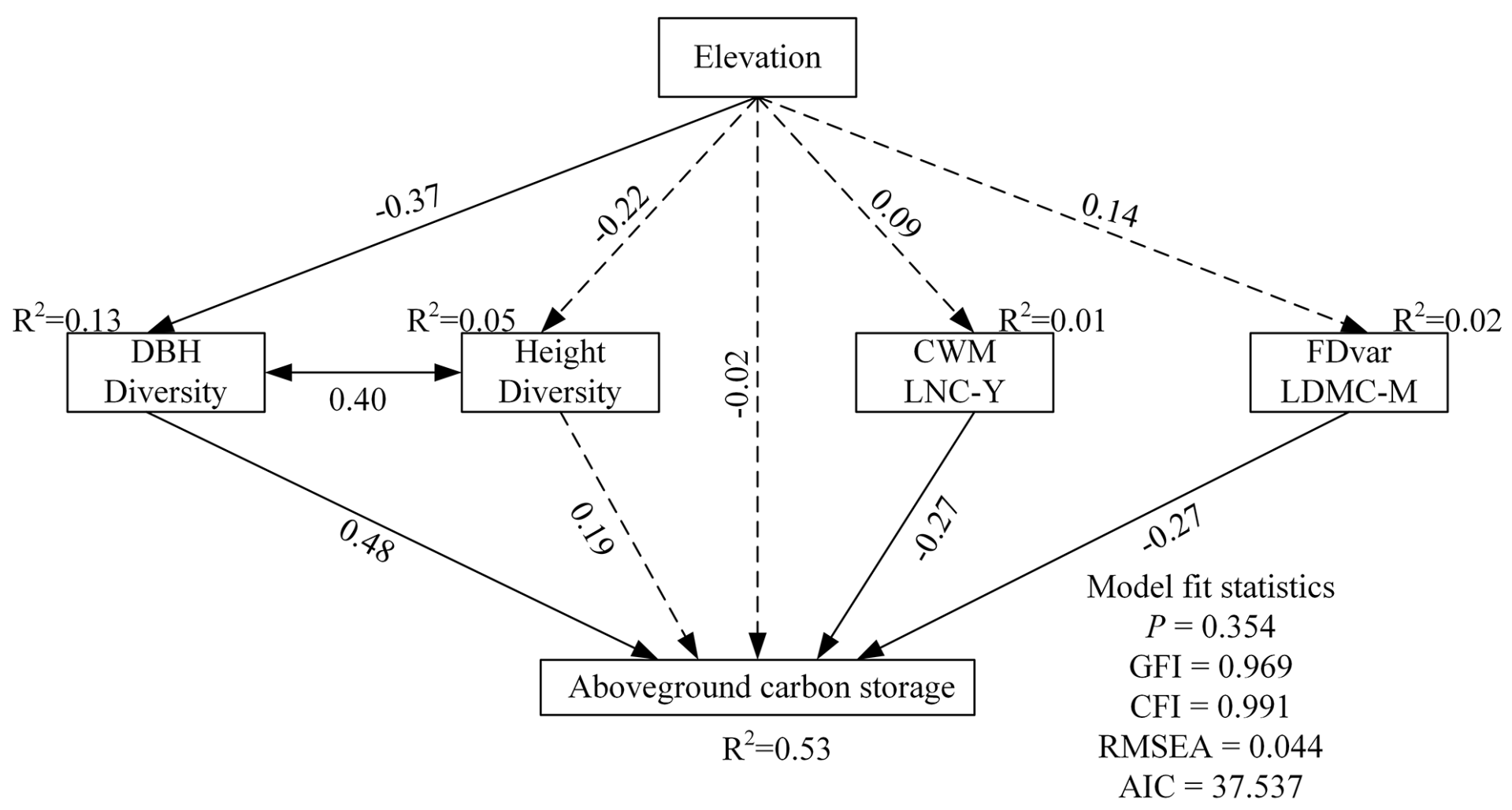

Figure 2

The optimal structural equation model relating aboveground carbon storage to predictor variables. Modelfit statistics and standardized regression coefficient of each path are shown in the figure. Significant routes and non-significant routes at the level of 0.05 were represented by solid arrows and dashed arrows, respectively. The total variation of the explained variable was showed as $\mathrm{R} 2$, which is explained by all the explanatory variables.

\section{Supplementary Files}

This is a list of supplementary files associated with this preprint. Click to download.

- Additionalfile1.docx

- Additionalfile2.xlsx 